\title{
Survey of Beef Quality Assurance on California dairies
}

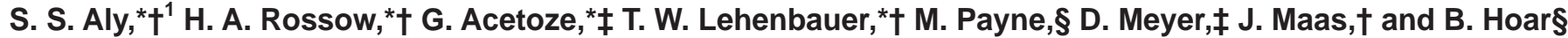 \\ *Veterinary Medicine Teaching and Research Center, School of Veterinary Medicine, University of California, Davis, Tulare 93274 \\ †Department of Population Health and Reproduction, School of Veterinary Medicine, University of California, Davis 95616 \\ ¥Department of Animal Science, University of California, Davis 95616 \\ $\S$ Western Institute of Food Safety and Security, University of California, Davis 95616
}

\begin{abstract}
In October 2011, a mail and online survey of California dairy personnel was conducted to assess producer familiarity with and support of the Dairy Animal Care and Quality Assurance (DACQA) program. The DACQA program addresses cattle of all ages (birth to culling) and standard practices that affect the use of dairy cattle for beef. The survey was mailed to a random sample of 1,071 California dairies (65\%) stratified by county, proportional to the number of dairies in each respective county. Data from the 158 responses received $(15 \%)$ showed that $90 \%$ of culled cows on California dairies were sold for beef. However, personnel on more than one-half of California dairies (56\%) had no knowledge of how their herd cull cows ranked in terms of beef quality measures (body condition score, US Department of Agriculture carcass grade, and hot carcass weight). Survey results showed that a considerable proportion of California dairy personnel were aware of recommended injection practices including a preference for subcutaneous injections (45\%). A drug inventory was maintained on approximately $50 \%$ of the state's dairies. Management at these dairies was twice as likely to test for drug residues compared with dairies that did not maintain a drug inventory. More information about the DACQA program was requested by more than half of California dairies.
\end{abstract}

Key words: Dairy Animal Care and Quality Assurance, California, injection practice, culling practice

\section{INTRODUCTION}

The Dairy Animal Care and Quality Assurance program (DACQA) is a national voluntary program available to US dairy producers through a joint effort of the national Beef Quality Assurance (BQA) program and the Dairy Herd Improvement Association (DHIA, 2009). The premise of DACQA is quality care of dairy

Received March 26, 2013.

Accepted November 8, 2013.

${ }^{1}$ Corresponding author: saly@ucdavis.edu cattle to ensure animal welfare, producer success, and production of a wholesome product that meets consumer expectation for food safety. The program goals are attained through guidelines for care of dairy cattle based on best management practices from birth to culling. The program guidelines are based on the national BQA and National Dairy Animal Well-Being Initiative Guidelines (NDAWI). The first BQA efforts began as Beef Safety Assurance in the 1970s, before being called BQA and aimed at producing beef that was free of chemical residues. In the 1990s, dairy states adapted BQA principles to what became known as the Dairy Beef Quality Assurance (DBQA) in both state and regional level programs. In 2008, the dairy industry formed the NDAWI.

In 2009, US dairy cattle cull rates varied between 22 and $27 \%$ annually and represented $8.6 \%$ of all slaughtered cattle. Of the 9.2 million dairy cattle in the United States, 1.8 million (almost 20\%) reside in California, which makes the state the largest source of dairy beef in the United States. Hence, a thorough understanding of current DACQA practices on California dairies and eliciting producer feedback about DACQA support are vital to potential deployment and adoption of the program in California. The driving questions for this survey focused on the need to understand current practices and identify the potential perceived value of DACQA educational opportunities for California. The survey highlighted key program components of culling and injection practices. The remaining study objectives were aimed at assessing dairy personnel's knowledge and familiarity with the DACQA program, identifying challenges in implementing the DACQA program on dairies, characterizing the population of dairy producers who may benefit from further DACQA program publicity, and reporting on dairy owners' general suggestions and feedback about DACQA.

\section{MATERIALS AND METHODS}

\section{Study Population and Sample Size Estimation}

A total of 1,650 licensed dairies in California were identified through a state list. Sample size estimation 
was performed to determine the proportion of dairy owners who are familiar with the DACQA program. A sample size of 156 dairies was deemed necessary to produce a $10 \%$ wide, 2 -sided $85 \%$ confidence interval for a hypothesized prevalence of $25 \%$ for dairies familiar with the DACQA program (Scheaffer et al., 1995). Furthermore, a 15\% survey response rate was assumed and hence the survey was mailed to 1,071 dairies.

The dairies selected for participation in the survey were randomly selected, stratified by county, and proportional to the number of dairies in each of California's 32 counties that have dairy farms. A confidential number specific to each dairy selected for participation in the survey was printed on the top of the survey and mailed to the respective address. No attempt was made to cross-match responses to premises to maintain confidentiality of responses. Participants who owned or managed more than one dairy were requested to answer the survey questions based on the dairy to which it was addressed.

\section{Survey}

Recommended methods to increase survey response rates were followed (Dillman, 2000), including newsletter announcements, industry meetings, and personal communications. The University of California, Davis Institutional Review Board exemption approval was acquired before sending the survey to selected dairies. The survey was mailed to each participating dairy twice, 2 wk apart, in October 2011. Each survey packet mailed contained an introductory cover letter explaining the goals of the survey, funding sources, authors, and method of providing feedback to the dairy industry, followed by a copy of the survey and finally a selfaddressed business reply envelope. Additionally, the survey was published online (www.surveymonkey.com). The survey comprised 52 unbiased, nonleading questions. Survey questions were grouped into 5 sections to collect information on the dairy's management, herd, cull dairy cows, medical treatments, and knowledge and implementation of BQA practices at the time of the survey. The majority of the survey questions required selection of the most appropriate answer; a few questions included the option of more than one selection where appropriate and an "other" or "none" option where necessary. Survey responses were received by an independent appointee and entered into a relational database and validated for integrity and completeness by a second appointee.

\section{Statistical Analysis}

Descriptive Statistics. Responses were classified according to the respondent's role on the dairy, years in business, and dairy as the income source (primary or not). Information was summarized on location (county), herd demographics, and dairy management, including type of records (computerized or paper-based), heifer raising (offsite or onsite), raising bull calves for beef, bST use, and whether or not the dairy was organic. The survey also included 2 questions about on-farm euthanasia methods used to euthanize calves and cows, respectively. Respondents were given the following options: firearm, captive bolt, euthanasia solution, or other.

Culling Dairy Cows for Beef on California Dairies. As a measure of the industry's interest in cull cows sold for beef, a scoring system was developed to describe the extent to which dairy personnel (owners, herd managers, both, or other) monitored their cull cows sold for beef. Responses were scored based on the respondent's knowledge of culled cows' BCS, mean hot carcass weight $(\mathbf{H C W})$, and US Department of Agriculture (USDA) carcass grade (UCG). A score of 0 was assigned to dairies having personnel who had no knowledge of their cull cows' BCS, HCW, and UCG. A higher score was assigned to those with knowledge of BCS, followed by HCW, and finally the highest score for those with knowledge of UCG. The gradient of scores was justified by the inherent level of detail as to beef quality in cull cows' BCS when sent to slaughter, their HCW after slaughter, and finally the cull cows' UCG. Furthermore, respondents were asked about the percentage of their cull cows sold for beef.

Drug Treatment Practices on California Dairies. Feasibility of administering treatment injections and following the DACQA program guidelines for cull cows was assessed based on participants' responses. In addition, personnel preferences to intramuscular (i.m.) or subcutaneous (s.c.) injection route and difficulties injecting cows in the neck compared with in the hind limbs were explored. The reported difficulties or concerns while administering injections in the neck or hind limb region were summarized. The proportion of respondents reporting difficulty injecting in the neck was compared with those reporting difficulty injecting in the hind limbs using a Wald test. Furthermore, method of cow restraint (headlocks, stanchion, chute, parlor, or behind gate) and direction from which a cow is approached for an injection in the neck (front or side) were explored as predictors of difficulty administering injections in the neck or hind limb separately using logistic regression (Equation [1]):

$$
\begin{aligned}
\operatorname{logit}[\mathrm{P}(\text { Difficulty injections })] & =\beta_{0}+\beta X_{\text {Headlocks }}+\beta X_{\text {Stanchion }}+\beta X_{\text {Chute }} \\
& +\beta X_{\text {Parlor }}+\beta X_{\text {Behind gate }}+\beta X_{\text {Front }}+\beta X_{\text {Side }},
\end{aligned}
$$


where $\beta_{0}$ is the intercept.

The survey offered 4 different types of difficulties that could be experienced while giving injections in either neck or hind limb. These included difficulty with logistics such as facilities, speed, or training; safety concern for personnel; safety concern for the cow; stressful for the cow; or "other." The different difficulty profiles reported were summarized.

The associations between maintaining a drug inventory (DI) and awareness of extra-label drugs (ELD) or extra-label drug use (ELDU), and the association between ELD and ELDU were explored using the Pearson $\chi^{2}$ test. Survey-weighted logistic regression models were also used to estimate the magnitude of the association between DI and ELD, and the association between DI and ELDU. Furthermore, the association between maintaining a DI and keeping track of drug withdrawal periods, and testing cows for drug residues were investigated.

Support for the DACQA Program. Survey results were analyzed to estimate the overall and county-specific proportion of California dairies whose personnel support the DACQA program. The remaining respondents were characterized into those that require more information, do not support the DACQA program, or would be supportive if paid to implement the program. Respondents' sources for information and preferred form of employee training were characterized to provide guidance on future education and outreach efforts for the DACQA program.

A survey-weighted logistic regression model was used to investigate the association between the survey questions and the respondent's support for the DACQA program. The outcome variable "support DACQA" was a dichotomous variable, with the levels "support" or "did not support" a voluntary certification program such as DACQA. The "did not support" response included those of "did not support," "needed more information to determine support" or "support if paid." Model selection was performed using a backward variable selection algorithm for any variable with a univariate model $P$-value $<0.30$. A variance-covariance matrix was estimated using a robust estimator of variance to account for clustering of responses within surveyed counties. Variables offered to the algorithm included average milking herd size (Herdsize), computer record keeping (CompRec), onsite heifer raising (OnsiteHeifers), cull to processor only (Processor), bST use (bST), stop injections $2 \mathrm{wk}$ before culling (StopInj), difficulty injecting in the neck region (DiffInjNeck), test milk or urine of culled cattle to avoid drug residue violations (AvoidResidue), use computer program to keep track of drug withdrawal periods (CompDW), familiar with ELD, and recent access to the DACQA website (DACQAWeb). The full model is summarized in Equation [2]:

$$
\begin{aligned}
\operatorname{logit}[\mathrm{P}(\mathrm{DACQA} \text { support })] & =\beta_{0}+\beta X_{\text {Herdsize }}+\beta X_{\text {CompRec }}+\beta X_{\text {OnsiteHeifers }} \\
& +\beta X_{\text {Processor }}+\beta X_{b S T}+\beta X_{\text {StopInj }} \\
& +\beta X_{\text {DiffInjNeck }}+\beta X_{\text {AvoidResidue }}+\beta X_{\text {CompDW }} \\
& +\beta X_{E L D}+\beta X_{\text {DACQAWeb }},
\end{aligned}
$$

where $\beta_{0}$ is the intercept.

To understand the respondents' decision process for their perception of the DACQA program, recursive partitioning using regression trees was used to analyze responses to the survey questions. Perception of the DACQA program was categorized into (1) supportive of the program; (2) not supportive; (3) require more information to decide; and (4) supportive if paid to implement the program.

BQA Practices Ranked by Importance. Producers were asked to rank a set of general BQA practices as well as injection practices. The general practices that respondents were asked to rank were drug residue avoidance, record keeping of medical treatments, cow health including lameness, injection practices, BCS, marketing and transport, and ration fed before marketing. Injection practices that respondents were asked to rank included training treatment crew, use of sharp and clean needles, choice of neck as the preferred injection site (drug label permitting), subcutaneous injections as the preferred injection route (drug label permitting), injection site cleanliness, drug volume per injection site limited to $10 \mathrm{~mL}$ maximum, and appropriateness of needle size. Practices were ranked from 1 to 5 , with 1 being the most important and 5 being the least important. The mean rank for each general BQA and injection practices from respondents who supported the DACQA program was compared with that from respondents who did not support the program.

All estimates were survey-weighted to account for the survey design and produce estimates relevant to the entire state (Scheaffer et al., 1995). A $5 \%$ level of significance was used for statistical significance. Analysis was performed in Stata 12.0 (College Station, TX) and using the rpart package loaded in $\mathrm{R} 2.15 .1$ environment (R Foundation for Statistical Computing, Vienna, Austria).

\section{RESULTS}

A total of $158(14.8 \%)$ responses from 19 counties were received within 3 mo of the second mailing of the survey (Table 1). Only 5 survey responses were received through the internet. The majority of respondents were owners of dairies in business for more than $20 \mathrm{yr}$ and 
Table 1. Frequency of dairies by county and responses received to a 2011 mail and internet survey of Beef Quality Assurance practices on California dairies

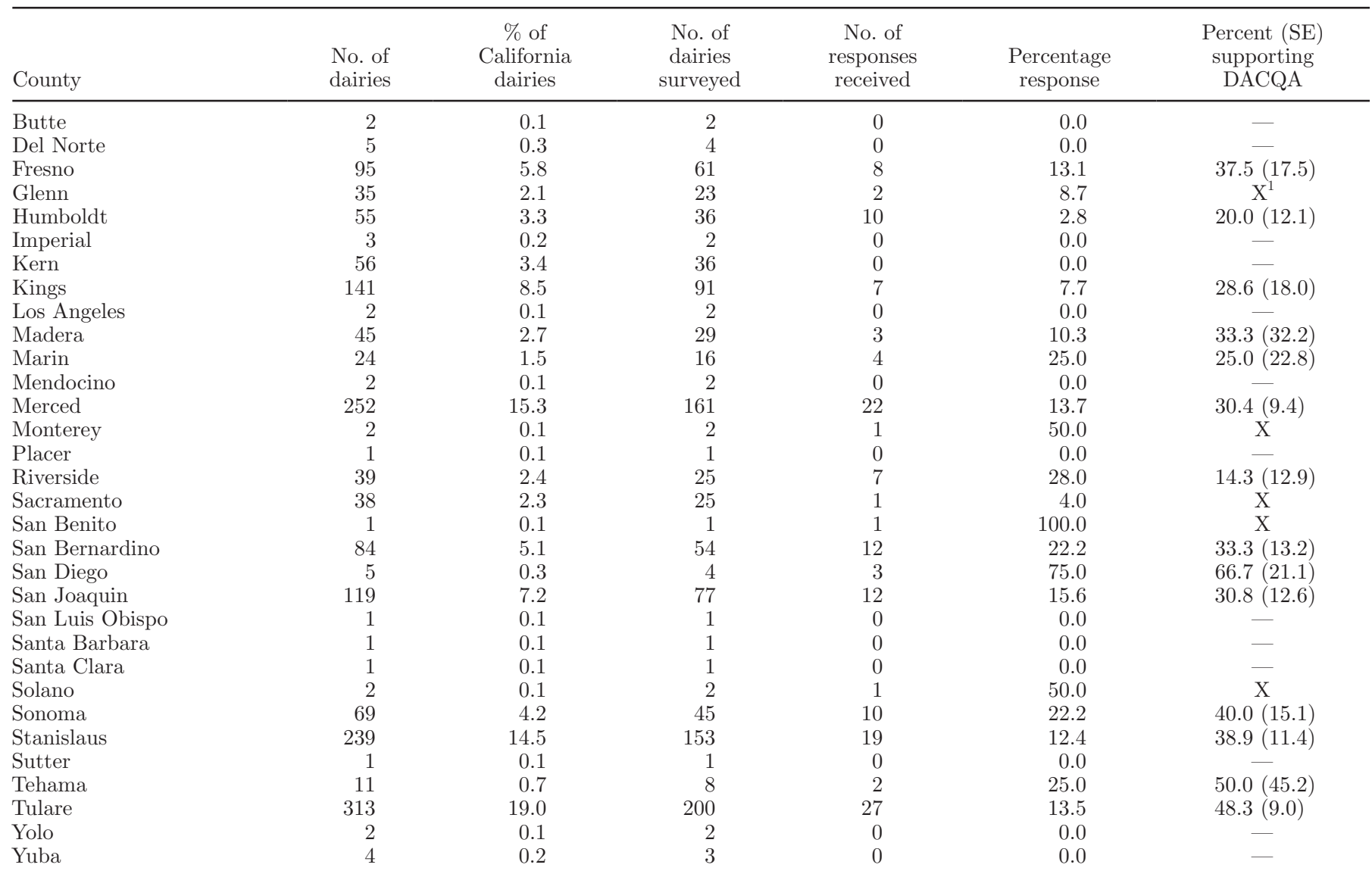

${ }^{1}$ Censored for counties where respondents had a unanimous decision about Dairy Animal Care and Quality Assurance (DACQA) support to avoid revealing respondents' identities.

with dairy being their primary source of income (Table 2 ). Herd characteristics provided by respondents are summarized in Table 3. Approximately 90.8\% (SE 2.4) of California dairies management reported selling newborn male calves for beef among options such as raising onsite or offsite either for beef or as replacement bulls. The majority of dairies euthanized cows and calves on farm, 95.9\% (SE 1.6) and 80.3\% (SE 3.5), respectively. Calf and cow euthanasia methods on California dairies are summarized in Table 4 . The survey-adjusted mean milking herd size was 1,298 cows (SE 108) and ranged from 65 to 5,500 cows; by comparison, the 2010 California Department of Food and Agriculture (CDFA) statistics of mean milking herd size by county was 1,090 and ranged from 85 to 3,179 cows (CDFA, 2011). Responses received represent a total of 176,930 milking cows or $9.5 \%$ of the state's milking herd (CDFA, 2011).

\section{Culling Dairy Cows for Beef on California Dairies}

The survey-weighted percentage of culled cows sold for beef purpose was estimated at 89.4\% (SE 2.1).
Moreover, 13.4\% (SE 2.7) of California dairies fed cull cows special diets before culling such as feeding a TMR or moving to pasture. Respondents (owners, herd managers, both, or others) had no knowledge of the frequency of their herd's culled cows by BCS categories. In contrast, $55.6 \%$ (SE 4.1) of California dairies scored 0 (had no knowledge of their cull cows' BCS, HCW, or UCG), 34.4\% (SE 3.9) scored 1 (had knowledge of their cull cows mean HCW only), and 10\% (SE 2.6) of dairies scored 2 (had knowledge of their cull cows mean HCW and UCG).

\section{Drug Treatment Practices}

Approximately 50.8\% (SE 3.8) of California dairies management chose i.m. as their preferred injection route, whereas $44.9 \%$ (SE 3.8) chose the s.c. route. The remaining $4.3 \%$ (SE 1.5) identified no preference. Additionally, personnel on $30.7 \%$ (SE 4.1 ) and $31.2 \%$ (SE 3.9) of California's dairies reported difficulty injecting in the neck and hind limbs, respectively $(P=0.9)$, whereas $15.1 \%$ (SE 2.9 ) reported difficulty in both. 
Table 2. Respondent's role, experience and dairy as their primary source of income in a 2011 survey of Beef Quality Assurance practices on California dairies

\begin{tabular}{|c|c|c|c|c|}
\hline \multirow[b]{2}{*}{ Item } & \multirow[b]{2}{*}{$\%$} & \multirow[b]{2}{*}{$\mathrm{SE}$} & \multicolumn{2}{|c|}{$95 \% \mathrm{CI}$} \\
\hline & & & Lower & Upper \\
\hline \multicolumn{5}{|l|}{ Respondent role } \\
\hline Owner & 73.6 & 3.5 & 66.6 & 80.5 \\
\hline Herd manager & 8.1 & 2.1 & 3.9 & 12.2 \\
\hline Owner and herd manager & 15.8 & 3.0 & 10.0 & 21.7 \\
\hline Other & 2.5 & 1.2 & 0.2 & 4.9 \\
\hline \multicolumn{5}{|l|}{ Years in dairy business } \\
\hline $0-10$ & 9.9 & 2.4 & 5.0 & 14.8 \\
\hline $10-20$ & 17.0 & 3.0 & 11.0 & 23.0 \\
\hline$>20$ & 73.1 & 3.6 & 66.1 & 80.2 \\
\hline \multicolumn{5}{|l|}{ Primary business } \\
\hline Dairy & 93.4 & 2.1 & 89.2 & 97.6 \\
\hline Not dairy & 6.6 & 2.1 & 2.4 & 10.8 \\
\hline
\end{tabular}

Restraining a cow using a stanchion or behind a gate were associated with an increase in odds of reporting difficulty giving injections in the neck region [odds ratio $(\mathrm{OR})=1.94, \mathrm{SE} 0.7, P=0.04 ; \mathrm{OR}=3.97, \mathrm{SE} 1.9, P=$ 0.004 , respectively]. Approaching a cow from the front was also associated with an increase in odds of difficulty giving injections in the neck region $(\mathrm{OR}=2.58$, SE 1.1, $P=0.03$ ). Restraining a cow behind a gate was associated with a decrease in odds of reporting difficulty giving injections in the hind limb $(\mathrm{OR}=0.16, \mathrm{SE}$ $0.10, P=0.003)$. The remaining restraining methods and direction a cow is approached when giving injections in either the neck or hind limb were not statistically significant. Survey responses formed 12 distinct "difficulty profiles," ranging from none to all 4 types of difficulties reported (Table 5). The most frequent difficulty reported for neck and hind limb injections was safety concern for personnel at 6.04\% (SE 1.82) and $15.40 \%$ (SE 2.87), respectively. Analysis of each of the 4 difficulties independently further confirmed that respondents on California dairies ranked safety concern for personnel while giving both neck and hind limb injections as the highest ranking difficulty $(11.4 \%$, SE $2.4 ; 21.2 \%$, SE 3.3). Logistics such as facility, speed, and training was ranked as the second most frequent profile of difficulty experienced giving injections in the neck region $(4.63 \%$, SE 1.87). In contrast, safety concern for personnel and cow was the second most frequent profile of difficulty experienced giving injections in the hind limb (2.28\%, SE 1.19).

Approximately 48.5\% (SE 4.0) of California dairies reported maintaining some form of a DI, 76.0\% (SE 3.3) were familiar with ELD, and 64.4\% (SE 3.9) reported ELDU. We observed no statistically significant association between maintaining a DI and familiarity with $\operatorname{ELD}(P=0.09)$ or ELDU $(P=0.7)$. However, as expected, familiarity with ELD and ELDU were significantly associated $(P<0.01)$. Based on survey responses, 97.3\% (SE 1.2) of California dairies tracked therapeutic drug withdrawal periods and $55.3 \%$ (SE

Table 3. Herd characteristics for dairies with a response to 2011 survey of Beef Quality Assurance practices on California dairies

\begin{tabular}{lrrrr}
\hline & & & \multicolumn{2}{c}{$95 \%$ CI } \\
\cline { 4 - 5 } Characteristic & & & Lower & Upper \\
\hline Herd size & & & & \\
Mean no. of milking cows & 1,298 & 108 & 1,084 & 1,512 \\
Breed (\%) & & & & \\
Holstein & 64.5 & 3.6 & 57.4 & 71.6 \\
Jersey & 6.1 & 1.7 & 2.7 & 9.5 \\
Mixed or other & 29.4 & 3.5 & 22.4 & 36.4 \\
Dairy records (\%) & & & & \\
Computer & 16.1 & 3.6 & 62.0 & 76.3 \\
Paper & 14.4 & 2.9 & 10.8 & 22.1 \\
Both & 5.8 & 1.7 & 9.0 & 19.8 \\
Offsite heifer raising (\%) & 8.5 & 2.2 & 2.2 & 9.3 \\
Bull calves raised for beef (\%) & 15.5 & 2.6 & 10.2 & 13.1 \\
Inject milking cows with bST (\%) & 9.5 & 1.9 & 5.7 & 13.7 \\
Organic dairy (\%) & & &
\end{tabular}


Table 4. Euthanasia methods on California dairies by age group based on responses from a 2011 Beef Quality Assurance survey

\begin{tabular}{|c|c|c|c|c|c|c|c|c|}
\hline Method & \multicolumn{4}{|c|}{ Calves } & \multicolumn{4}{|c|}{ Cows } \\
\hline \multicolumn{9}{|l|}{ Among other methods } \\
\hline Captive bolt & 6.2 & 2.1 & 2.0 & 10.4 & 7.3 & 2.2 & 2.9 & 11.7 \\
\hline Firearm & 61.1 & 3.9 & 53.3 & 68.8 & 78.0 & 3.3 & 71.4 & 84.6 \\
\hline Captive bolt only & 4.8 & 1.9 & 1.0 & 8.5 & 4.8 & 1.9 & 1.0 & 8.5 \\
\hline Firearm only & 56.3 & 4.0 & 48.4 & 64.3 & 75.6 & 3.4 & 68.8 & 82.4 \\
\hline Euthanasia solution only & 2.5 & 1.2 & 0.1 & 4.9 & 5.0 & 1.7 & 1.6 & 8.4 \\
\hline Other & $30.9^{1}$ & 3.6 & 23.8 & 38.1 & $10.8^{1,2}$ & 2.5 & 5.7 & 15.8 \\
\hline
\end{tabular}

${ }^{1}$ Do not euthanize calves.

${ }^{2}$ No response.

4.1) used computer programs to do so. Furthermore, $17.0 \%$ (SE 3.2) of California dairies tested cows for therapeutic drug concentrations as part of their withdrawal tracking. Although not statistically significant, dairies with management reporting some form of a DI were 2.2 times as likely to track withdrawal periods $(P$ $=0.34$ ) than those who did not have a DI. In contrast, dairies with management that maintained some form of a DI were 3.0 times more likely to test cows for drug residues $(P=0.02)$. Specifically, $16.7 \%$ (SE 3.2) of California dairies tested milk or urine of their cull cows for drug residues.

\section{Support for the DACQA Program}

The survey indicated that $34.7 \%$ (SE 0.40 ) of operations were supportive of the DACQA program compared with $20.8 \%$ (SE 0.30) who were not. Table 1 summarizes the distribution of respondents by county and support of the DACQA program. Furthermore, $44.5 \%$ (SE
0.40) of the state's dairies had personnel who requested more information about the DACQA program before making a decision to support the program. The latter may be an indication that support for the DACQA program in California may increase with more education and outreach. Few dairies suggested a monetary-based implementation program (1.5\%; SE 0.01).

Approximately half (52.4\%; SE 4.0) of the dairies had personnel who received no education or outreach material on the DACQA program from any source. In contrast, veterinarians were the most common source for information on BQA recommendations (22.8\%; SE 3.5 ) followed by nutritionists, feed companies, and pharmaceutical industry representatives combined (20.6\%; SE 3.4). In addition, 4.3\% (SE 1.6) of dairies' personnel reported that their milk processor provided information to them on the DACQA program. As to the form of employee training on beef quality practices, $36.9 \%$ (SE 3.9) of the dairies had personnel who preferred a direct form such as wet labs, meetings, or workshops.

Table 5. Types of difficulty reported by respondents of a survey for Beef Quality Assurance on California dairies in 2011

\begin{tabular}{|c|c|c|c|c|c|c|c|c|}
\hline \multirow[b]{2}{*}{ Profile } & \multicolumn{4}{|c|}{ Type of difficulty reported with injections } & \multicolumn{4}{|c|}{ Injection site } \\
\hline & $\begin{array}{l}\text { Logistics (facilities, } \\
\text { speed and training) }\end{array}$ & $\begin{array}{l}\text { Safety concern } \\
\text { for personnel }\end{array}$ & $\begin{array}{l}\text { Safety concern } \\
\text { for cow }\end{array}$ & $\begin{array}{l}\text { Stressful } \\
\text { for cow }\end{array}$ & $\%$ & $\mathrm{SE}$ & $\%$ & $\mathrm{SE}$ \\
\hline 0 & No & No & No & No & 80.60 & 3.27 & 76.61 & 3.42 \\
\hline 1 & No & No & No & Yes & 1.63 & 1.29 & 0.69 & 0.66 \\
\hline 2 & No & No & Yes & No & 0.76 & 0.73 & 0.76 & 0.73 \\
\hline 5 & No & Yes & No & Yes & 1.14 & 0.80 & 0.73 & 0.47 \\
\hline 6 & No & Yes & Yes & No & 1.45 & 0.98 & 2.28 & 1.19 \\
\hline 7 & No & Yes & Yes & Yes & 1.17 & 0.82 & 0.87 & 0.73 \\
\hline 8 & Yes & No & No & No & 4.63 & 1.87 & 0.70 & 0.67 \\
\hline 9 & Yes & Yes & No & No & - & - & 1.27 & 0.86 \\
\hline 10 & Yes & No & Yes & Yes & 0.44 & 0.41 & - & - \\
\hline 11 & Yes & Yes & Yes & Yes & 1.56 & 0.98 & 0.69 & 0.66 \\
\hline
\end{tabular}


Table 6. Estimates from a survey-weighted logistic regression model for the association between management variables and producer support for a Beef Quality Assurance program on California dairies in 2011

\begin{tabular}{|c|c|c|c|c|c|}
\hline \multirow[b]{2}{*}{ Predictor } & \multirow[b]{2}{*}{ Odds ratio } & \multirow[b]{2}{*}{ SE } & \multirow[b]{2}{*}{$P$-value } & \multicolumn{2}{|c|}{$95 \%$ CI } \\
\hline & & & & Lower & Upper \\
\hline $\begin{array}{l}\text { Management stops injecting cows with treatments } \\
\text { at least } 2 \text { wk before culling }\end{array}$ & 3.66 & 1.54 & 0.002 & 1.60 & 8.35 \\
\hline $\begin{array}{l}\text { Staff administering injections experience difficulty } \\
\text { injecting treatments in the neck region }\end{array}$ & 3.35 & 1.50 & 0.007 & 1.39 & 8.07 \\
\hline Awareness with extra-label drug use & 2.87 & 1.32 & 0.02 & 1.17 & 7.09 \\
\hline $\begin{array}{l}\text { Respondent recently accessed the Dairy Animal Care } \\
\text { and Quality Assurance program website }\end{array}$ & 36.35 & 53.03 & 0.01 & 2.08 & 634.34 \\
\hline
\end{tabular}

In contrast, 24.9\% (SE 3.3) preferred an indirect form of training such as a poster or video presentation for employee training. Furthermore, 30.0\% (SE 3.7) of respondents indicated that either form, direct or indirect, was acceptable. Only 8.3\% (SE 2.2) did not identify a preferred form of training for their employees.

Results of the final logistic regression model for the associations between the survey factors and the dairies' support for the DACQA program are summarized in Table 6. Recent access to the DACQA program's website was the variable most associated with support for the program. Producers who did not inject cull dairy cows during the 2 wk before culling, producers who used computers to track withdrawal periods, those who had difficulty injecting drugs in the neck region, those who culled dairy cows to processors only, or those who were familiar with ELDU were more supportive of the DACQA program compared with producers who did not. Testing milk and urine of cull dairy cows before culling was not significantly associated with support for the DACQA program.

The regression tree resulting from recursive partitioning of the survey question responses with support of the DACQA being the outcome is summarized in Figure 1. Recursive partitioning showed that recent access to the DACQA website, herds with a rolling herd average $\geq 8,568 \mathrm{~kg}$, and culling rates $>29.5 \%$ identified dairies that generally either supported the program or needed more information about DACQA. An exception to the latter was large herds ( $>1,350$ milking cows), with exceedingly high cull rates $(>32.5 \%)$, that euthanized calves on farm, and had a percentage culled sold for beef $<96.5 \%$; herds that fit that profile tended to not support the program. Low-producing herds (rolling herd average $<8,568 \mathrm{~kg}$ ) also tended to either support or need more information on the program depending on their percentage culled sold for beef, whether the herd management maintained a drug inventory or indicated ELDU.

\section{BQA Practices Ranked by Importance}

The mean rank for each of the general and injection practices did not differ significantly between dairies with management that were supportive compared with dairies that were not supportive of the DACQA program. Respondents ranked the BQA general practices in descending order of importance (and mean rank) as drug residue avoidance $(1.4, \mathrm{SE}=0.02)$, medical treatment recordkeeping $(2.2, \mathrm{SE}=0.04)$, cow health including lameness $(2.6, \mathrm{SE}=0.04)$, injection practices $(2.9, \mathrm{~S}=0.04), \mathrm{BCS}(3.6, \mathrm{SE}=0.05)$, marketing and transport $(3.9, \mathrm{SE}=0.05)$, and ration fed before marketing $(4.8, \mathrm{SE}=0.06)$. Respondents ranked injection practices in descending order of importance starting with training treatment crew $(1.8, \mathrm{SE}=0.04)$, neck as the preferred injection site $(2.4, \mathrm{SE}=0.05)$, use of sharp and clean needles $(2.6, \mathrm{SE}=0.05)$, injection site cleanliness $(2.7, \mathrm{SE}=0.05)$, appropriateness of the needle size $(3.1, \mathrm{SE}=0.05)$, subcutaneous injection as the preferred injection route $(3.2, \mathrm{SE}=0.1)$, and drug volume per injection site limited to $10 \mathrm{~mL}(3.3, \mathrm{SE}=$ $0.05)$.

\section{DISCUSSION}

The survey was mailed to a representative sample of the California dairy industry at a period of heightened alert due to the possibility of new regulations for drug residue surveillance. Such increased awareness may have contributed to the slightly higher than expected response rate. Compared with state statistics, respondents had herd demographics (herd size, breed, and dairy personnel experience and age profile) that were similar to those of the state. However, the survey estimated that $9.8 \%$ of the state dairies were organic, which may be an overestimate given that respondents were not specifically provided with a definition of organic; in contrast, the USDA estimate is $5.3 \%$ in California 


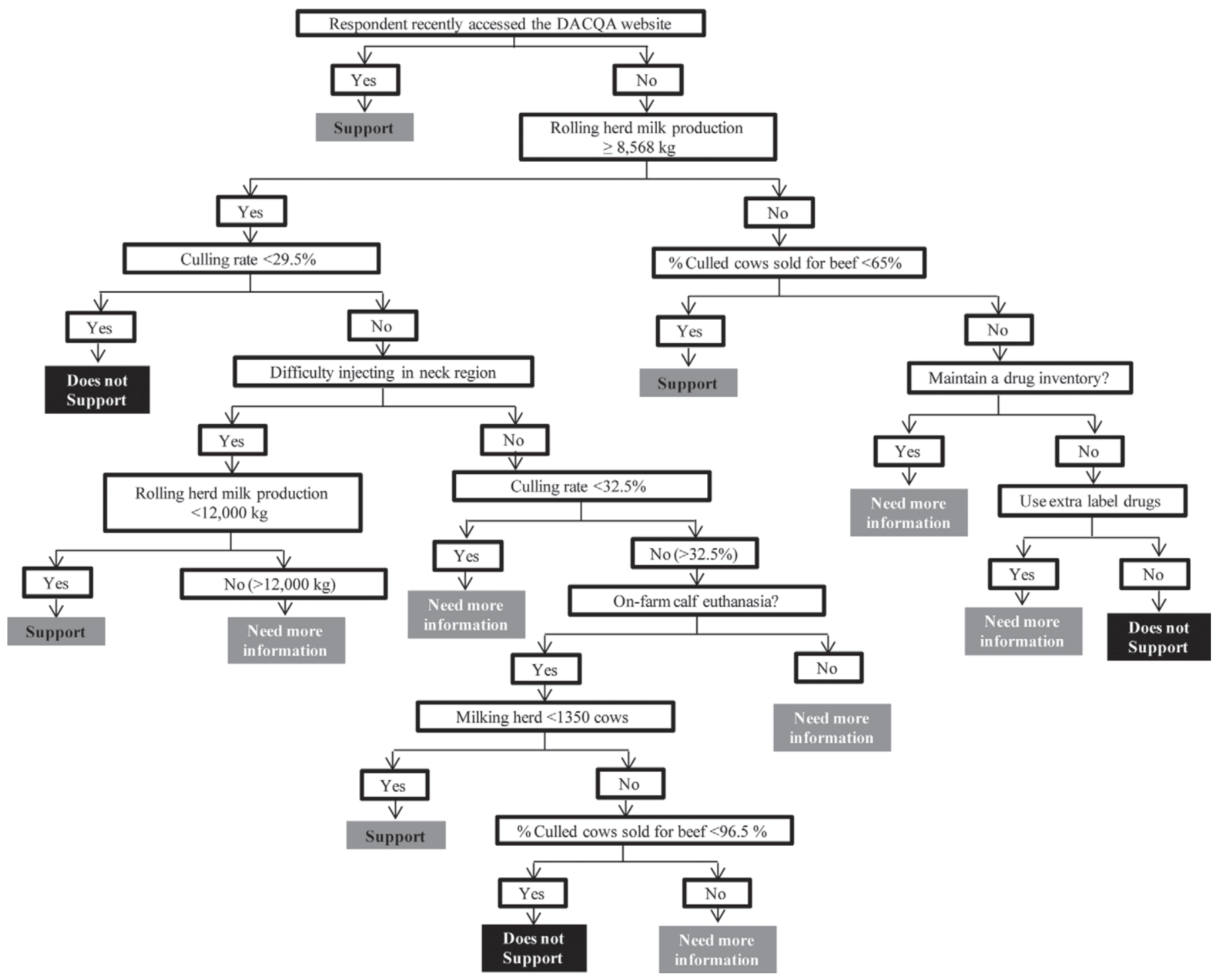

Figure 1. Regression tree for producer support of a Beef Quality Assurance program on California dairies in 2011. DACQA = Dairy Animal Care and Quality Assurance program.

for the year 2011 (USDA, 2012). Hence, producers who do not use bST or dry cow therapy may consider their operations organic when, in fact, they may not meet a stricter definition for an organic dairy. The majority of California dairies euthanized calves and cows using firearms both exclusively and among other euthanasia methods, a finding in agreement with the authors' experiences with management on California dairies. The second most reported method of euthanasia was captive bolt for calves and cows. Interestingly, 30.9\% of respondents indicated that they do not euthanize calves. Such a high percentage could be due to calves being raised offsite. Another explanation may be due to the increase in sale price of male calves sold and fed for beef.
An interesting study finding was that approximately $90 \%$ of culled cows on California dairies were sold for beef. The high percentage sold for beef was based on respondents' reported estimates and hence may not include cows sold at sale barns and that may be purchased again as dairy animals. Despite the tendency of dairy personnel to sell more cull dairy cows for beef, personnel on more than half of California dairies had no knowledge of how their cull cows ranked in terms of BCS, HCW, or UCG. In addition, although HCW and UCG data may not be readily available to dairy personnel, a simplified BCS could be captured with minimal training. A considerable proportion of dairy personnel were able to provide mean HCW and UCG, which is information that meat packers routinely send owners 
with payments for their cull dairy cows. The fact that respondents indicated knowledge of $\mathrm{HCW}$ and UCG showed that owners showed interest in and monitored how their cull cows ranked as beef animals. A simplified BCS system for dairy cows at culling may benefit the DACQA, justified by absence of the need to score cows in 0.25-unit increments. A more realistic scoring system would be one that correlates with UCG and may be limited to the main grades that capture the majority of variability in cull dairy cow carcasses.

Most BQA recommendations include administering treatments in the neck region and preferably subcutaneously to avoid muscle damage. Management on California dairies was approximately split with regards to preference for injection site, with the most frequent difficulty being safety concerns for personnel giving injections in the neck or hind limb. Beyond the safety concern for personnel giving injections in the neck region, respondents also reported concern as to logistics. The logistics indicated in the survey included inadequate facilities, speed at which injections can be administered, and the need for proper training on administering injections in the neck when cows are locked up. In contrast, beyond safety concern for personnel administering injections in the hind limb, respondents raised concerns for cow safety. Cow safety can be a concern when administering injections in the hind limb possibly because of trauma to the cow. Injection preferences of dairy personnel showed that a considerable proportion were aware of recommended injection practices, including a preference for subcutaneous injections and administering injections in the neck. However, an equal proportion showed other preferences justifying targeting injection practices in future efforts to publicize DACQA.

Our survey estimated that more than half of the dairies' management were familiar with ELD. Of those familiar with ELD, ELDU was independent of maintaining a DI or not. This may indicate that future DACQA education should emphasize the importance of maintaining a DI, specifically in dairies familiar with ELD. Conversely, the finding that maintaining a DI was not associated with ELD familiarity or ELDU shows a trait indicative of responsible handling of on-farm drugs. An additional benefit of having a DI could be decreased likelihood of a drug residue violation, because dairies that maintained a DI were twice as likely to test for drug residues. Furthermore, the statistic that almost all California dairies reported keeping track of withdrawal periods may be biased by a coinciding proposal for stricter drug residue monitoring by the US Food and Drug Administration.

Responses that indicated culling directly to a processor, avoiding any injections 2 wk before culling, using computer records to keep track of withdrawal periods, or familiarity with ELD were significantly associated with support of the DACQA program, as described in the program's guidelines. Furthermore, recent access to the DACQA website was the variable most associated with support for the program as confirmed by both logistic regression and regression tree analysis. The survey did not include a description, address, or an image for the program's website, which may have resulted in respondents assuming a different program, such as the national Farmers Assuring Responsible Management (FARM) program that was concurrently being self-implemented in California led by the milk processors and cooperatives. However, it is unlikely that respondents confused these 2 programs, given the low number of respondents indicating familiarity with DACQA.

Interestingly, respondents ranked the general BQA practices similarly regardless of their support of the DACQA program. Specifically, respondents ranked drug residue avoidance as the most important BQA practice whereas ration fed before marketing ranked lowest. In addition, medical treatment recordkeeping and cow health ranked higher than injection practices and marketing. Similarly, respondents who supported the DACQA program and those that did not ranked training of treatment crew as the most important injection practice, whereas drug volume per injection site was lowest. Preference for injecting treatments in the neck region ranked higher than use of sharp needles, injection site cleanliness, needle size, or subcutaneous route of injection. The similarity in respondents who support the DACQA program and those who do not can be interpreted as equal awareness and interest. Survey results indicated that very few dairy operators were familiar with the DACQA website, the major source of the program's manual and related information. Increased publicity for the program would also be beneficial because personnel on approximately half of California's dairies specifically requested more information on the program. A BQA certification program may be supported by the California dairy industry.

\section{ACKNOWLEDGMENTS}

Funding for this survey was made possible by the Beef CheckOff program and the Dairy Epidemiology Laboratory (S. S. Aly) at the Veterinary Medicine Teaching and Research Center (VMTRC, University of California, Davis). The authors thank personnel of the dairies for participating, different industry groups and publication editors for survey advertisement, and undergraduates Tara Urbano and Jianyang Zhao (VMTRC, University of California, Davis) for technical assistance. 


\section{REFERENCES}

CDFA (California Department of Food and Agriculture). 2011. 2011 California Dairy Statistics Annual. Accessed Dec. 19, 2013. http://www. cdfa.ca.gov/dairy/pdf/Annual/2011/2012_Annual_2011_Data. pdf.

DHIA. 2009. Dairy Animal Care and Quality Assurance program. Accessed Dec. 19, 2013. http://www.bqa.org/CMDocs/bqa/ DairyBQAManual.pdf.
Dillman, D. A. 2000. Mail and Internet Surveys: The Tailored Design Method. 2nd ed. Wiley, New York, NY.

Scheaffer, R. L., W. Mendenhall, and R. L. Ott. 1995. Elementary Survey Sampling. 5th ed. Duxbury Press, Belmont, MA.

US Department of Agriculture. 2012. 2011 Certified Organic Production Survey. Accessed Dec. 19, 2013. http://usda01.library. cornell.edu/usda/current/OrganicProduction/OrganicProduction10-04-2012.pdf. 